\title{
CARBAPENEMASE PRODUCING ENTEROBACTERIACEAE AMONG URINARY ISOLATES: SCENARIO FROM A TERTIARY CARE HOSPITAL IN EASTERN INDIA
}

\author{
Rajkumar Manojkumar Singh¹, Soma Sarkar², Puranjay Saha ${ }^{3}$, Manideepa Sengupta4
}

\section{HOW TO CITE THIS ARTICLE:}

Rajkumar Manojkumar Singh, Soma Sarkar, Puranjay Saha, Manideepa Sengupta. "Carbapenemase Producing Enterobacteriaceae among Urinary Isolates: Scenario from a Tertiary Care Hospital in Eastern India". Journal of Evolution of Medical and Dental Sciences 2014; Vol. 3, Issue 06, February 10; Page: 1323-1333,

DOI: $10.14260 /$ jemds/2014/1987

ABSTRACT: BACKGROUND: Carbapenemases are emerging resistance determinants in Gramnegative pathogens, including Pseudomonas aeruginosa, Acinetobacter spp and Enterobacteriaceae. Acquired carbapenem resistance is largely attributed to the production of carbapenem-hydrolysing enzymes called carbapenemases which include metallo-beta-lactamases (MBLs) or Klebsiella pneumoniae carbapenemases (KPCs). Detection of these enzymes has become a diagnostic challenge for clinical microbiologists. The present study was undertaken to assess the incidence of carbapenemases including KPCs and MBLs in urinary isolates of Enterobacteriaceae. MATERIALS AND METHODS: A total of 66 consecutive, non-repeat carbapenems resistant (by disk diffusion) clinical isolates of Enterobacteriaceae obtained over a period of one year (January-December, 2011) were subjected to modified Hodge test (MHT) for the detection of carbapenemases, combined disk test using phenylboronic acid(PBA) for KPC, EDTA double disk synergy test, combined disk test using EDTA, MBL Etest for MBL, and disk enhancement test with both PBA and EDTA for detecting coproduction of KPC and MBL. RESULTS: Of the total 66 resistant clinical isolates, MHT identified 61 (92.42\%) isolates as carbapenemase producers, metallo-beta-lactamases (MBLs) activity was detected in 39(59.09\%) isolates, KPC in 9(13.63\%) and co-existent of both KPC and MBL in 3(4.54\%) isolates. CONCLUSIONS: The study demonstrates the presence of carbapenemases including KPCs and MBLs in Enterobacteriaceae in our hospital. The combined disk test and MBL Etest show equal efficacy for MBL detection, but given the cost-constraints, combined disk test can be used as a convenient detection method in the clinical microbiology laboratory. Boronic acid disk test is easy to perform, interpret and reliable method in detecting KPCs.

KEYWORDS: Carbapenemases, KPCs, MBLs, eastern India.

INTRODUCTION: Carbapenems, first introduced in 1980, are the potent antibiotics for the treatment of infections due to multi-resistant gram-negative bacteria, including those with extended spectrum $\beta$-lactamases (ESBLs) and AmpC $\beta$-lactamases ${ }^{1}$. The clinical utility of these antimicrobials is under threat with the emergence of carbapenemases, diverse group of enzymes which are mainly of three types -Ambler class A (like KPC enzymes, SME), Ambler class B (metallo- $\beta$-lactamases, MBLs), and Ambler class D (oxacillinases, OXAs) ${ }^{2}$. A particular concern is that these enzymes are located on integron structures that reside on mobile genetic elements such as plasmids or transposons, thus enabling widespread dissemination among the gram negative fraternity ${ }^{3}$. Pseudomonas aeruginosa and Acinetobacter spp in particular are most often associated with carbapenem resistance 3 . In recent years, these enzymes have spread from P. aeruginosa to members of the Enterobacteriaceae ${ }^{4,5}$. 
The first known carbapenem resistant Enterobacteriaceae was discovered in 1991 when the metallo $\beta$-lactamase (MBL) gene blaIMP-1 was isolated in Serratia marcescens from Japan6. This was subsequently followed by identification of blaVIM-1 and blaKPC in Greece and United States ${ }^{7,8}$. Recently, the New Delhi Metallo-Beta Lactamase-1 (NDM-1) has been detected from an isolate of Klebsiella pneumoniae from a Swedish patient of Indian origin ${ }^{1}$.

Several non-molecular techniques have been studied, all taking advantage of the enzyme's zinc dependence by using chelating agents, such as EDTA or 2 mercaptopropionic acid, to inhibit its activity ${ }^{9}$. Despite PCR being highly accurate and reliable, its accessibility is often limited to reference laboratories9. In 2009, Clinical and Laboratory Standards Institute (CLSI) incorporated the modified Hodge test (MHT) for the detection of carbapenemases, especially for Klebsiella pneumonia carbapenemases (KPCs) ${ }^{10}$.

Although a global increase in the incidence of carbapenemases including MBL producing nonfermenting gram negative bacilli and Enterobacteriaceae has been reported, limited data is available from our region of India. The present study was conducted in a tertiary care hospital of eastern India with an aim to explore the occurrence of carbapenemases among the nosocomial urinary isolates of Enterobacteriaceae which were further tested phenotypically for KPC and MBL production.

\section{METHODOLOGY:}

Bacterial isolates: A total of 996 consecutive, non-duplicate isolates of Enterobacteriaceae recovered from 4272 urine specimens of patients of all age groups and both sexes hospitalized for $>48$ hours over a period of one year (January to December, 2011) were included in this prospective study. Identification of the isolates was determined using conventional methods 11.

Antibiotic susceptibility testing: Antimicrobial susceptibility testing was carried out by the KirbyBauer disk diffusion method following current CLSI guidelines ${ }^{10}$, using commercially available $6 \mathrm{~mm}$ disks (HIMEDIA, Mumbai, India) cefotaxime $(30 \mu \mathrm{g})$, ceftriaxone $(30 \mu \mathrm{g})$, ceftazidine $(30 \mu \mathrm{g})$, cefepime $(30 \mu \mathrm{g})$, meropenem $(10 \mu \mathrm{g})$, imipenem $(10 \mu \mathrm{g})$, aztreonam $(10 \mu \mathrm{g})$, gentamicin $(10 \mu \mathrm{g})$, amikacin $(30 \mu \mathrm{g})$, piperacillin $(100 \mu \mathrm{g})$, pipercillin-tazobactam $(100 / 10 \mu \mathrm{g})$, ciproploxacin $(5 \mu \mathrm{g})$, levofloxacin $(5 \mu \mathrm{g})$, polymyxin B (300 units), colistin $(10 \mu \mathrm{g})$, tigecycline $(15 \mu \mathrm{g})$ and cotrimoxazole $(1.25 / 23.75 \mu \mathrm{g})$ on Mueller Hinton agar plate.

Screening for carbapenamases: The isolates that showed reduced sensitivity or resistance to imipenem and meropenem by disk diffusion method were tested for carbapenamases including MBL and $\mathrm{KPC}^{10}$.

MIC by agar dilution method ${ }^{10}$ : MIC of screening positive isolates, for imipenem and meropenem, was determined by agar dilution method at the dilution range from 0.5 to $256 \mathrm{mcg} / \mathrm{ml}$.MICs interpretative criteria followed published guidelines established by the CLSI (2010).

\section{Detection of carbapenamases}

Modified Hodge Test: The detection of carbapenamases was done by the modified Hodge Test as suggested by Lee et al 12,13. An overnight culture suspension of E.coli coli ATCC 25922 which was adjusted to one- tenth turbidity of the McFarland 0.5 tube was inoculated evenly on the surface of a 
Muller-Hinton agar plate using a sterile cotton swab. After a brief drying at room temperature, an imipenem disk $(10 \mu \mathrm{g})$ was placed in the center of the plate. Carbapenem resistant test strains from an overnight culture were streaked heavily from the edge of the disk to the periphery of the plate. The presence of a distorted or clover leaf shaped inhibition zone was interpreted as positive for carbapenemase producing isolates.

Detection of KPC: Use of inhibitor phenylboronic acid (PBA) along with meropenem disk, described by Tsakris A et al, was used for detection of KPC 14,15.

The stock solution of PBA in the concentration of $20 \mathrm{mg} / \mathrm{ml}$ was prepared by dissolving 120 mg of PBA (HIMEDIA, Mumbai, India) in $3 \mathrm{ml}$ of dimethyl sulfoxide (DMSO) followed by adding $3 \mathrm{ml}$ of sterile distilled water. Twenty microliters ( $400 \mu \mathrm{g}$ of PBA) from this solution was dispensed onto meropenem discs. Disks were allowed to dry for $30 \mathrm{~min}$ and used immediately or stored in airtight vials with desiccant at 4 and at $-70^{\circ} \mathrm{C}$. The boronic acid disk test was performed on Mueller-Hinton agar by placing a disk containing $10 \mu \mathrm{g}$ of meropenem and a disk containing $10 \mu \mathrm{g}$ of meropenem and $400 \mu \mathrm{g}$ of boronic acid onto the agar. Inoculated plates were incubated overnight at $35^{\circ} \mathrm{C}$. Production of KPC was considered when the growth-inhibitory zone diameter around the meropenem disc with PBA was increased $\geq 5 \mathrm{~mm}$ compared with the growth-inhibitory zone diameter around the disc containing meropenem alone.

\section{Detection of metallo-beta-lactamases}

1. EDTA double disk synergy test (DDST): The imipenem-EDTA double disc synergy test was performed as described by Lee et al and Arakawa et al 13,16 .

A $0.5 \mathrm{M}$ EDTA solution was prepared by dissolving $186.1 \mathrm{~g}$ of disodium EDTA.2 $\mathrm{H}_{2} \mathrm{O}$ (RANCHEM, New Delhi, India) in 1, $000 \mathrm{ml}$ of distilled water. The $\mathrm{pH}$ was adjusted to 8.0 by using $\mathrm{NaOH}$ (HI-MEDIA, Mumbai, India) and was sterilized by autoclaving.

EDTA disks ( $6 \mathrm{~mm}$ in diameter, Whatman filter paper no.1) were prepared by incorporating $10 \mu \mathrm{l}$ of $0.5 \mathrm{M}$ solution of EDTA on blank disks (equivalent to $750 \mu \mathrm{g}$ per disk). The test organisms were adjusted to a 0.5 McFarland turbidity standard and inoculated on Mueller Hinton agar plates as recommended by the CLSI. The EDTA disk was placed $20 \mathrm{~mm}$ apart edge to edge from the imipenem disk and the plates were incubated overnight at $35^{\circ} \mathrm{C}$. A zone of synergy between the antibiotic disk and EDTA was taken as a positive result.

2. Combined disk test: The combined disk test or the disk enhancement test was performed as described by Yong et al17.Test organisms were inoculated on Mueller Hinton agar plates as recommended by the CLSI. Two $10 \mu \mathrm{g}$ imipenem disks were placed on the plate, and $10 \mu \mathrm{L}$ of EDTA solution was added to one of them to obtain the desired concentration $(750 \mu \mathrm{g})$. The inhibition zones of the imipenem and imipenem-EDTA disks were compared after 16 to 18 hours of incubation at $35^{\circ} \mathrm{C}$. An increase of $\geq 7 \mathrm{~mm}$ in zone inhibition diameter around the imipenem and EDTA disk in comparison to the imipenem disk alone was interpreted as a positive result for MBL production.

3. MBL Etest: MBL E test strips (HIMEDIA, INDIA) is a double-sided strip consisting of meropenem (MRP) (4 to $256 \mu \mathrm{g} / \mathrm{ml}$ ) on one side and meropenem plus EDTA (1to $64 \mu \mathrm{g} / \mathrm{ml}$ ) on the other. The E- 
test was done according to manufacturer's instructions. The presence of MBL is indicated by a reduction of MRP MIC $\geq 3$ twofold dilutions in the presence of EDTA (ratio of MRP/MRP+EDTA of $\geq 8$ ) or the appearance of phantom zones, or deformation of ellipses.

Co-production of MBL and KPC15: On Mueller Hinton agar plate inoculated with test strain, four disks of meropenem were used. One disk of meropenem was without any inhibitor, one disk with PBA $(400 \mu \mathrm{g})$ only, one disk with EDTA $(10 \mu \mathrm{L}$ of $0.5 \mathrm{M})$ only and fourth disk of meropenem had both PBA plus EDTA. The agar plates were incubated at $37^{\circ} \mathrm{C}$ overnight and the diameter of the growth inhibitory zone around these meropenem discs with inhibitor added was compared with that around the plain meropenem disc. Production of both KPC and MBL enzymes was considered when the growth-inhibitory zone diameter around the meropenem disk with both PBA and EDTA was increased $\geq 5 \mathrm{~mm}$ compared with the growth-inhibitory zone diameter around the disk containing meropenem alone while the growth-inhibitory zone diameters around the meropenem disk with PBA and the meropenem disc with EDTA were increased $<5 \mathrm{~mm}$ compared with the growth-inhibitory zone diameter around the disk containing meropenem alone.

Quality control: Reference strains of carbapenemases positive K. pneumoniae ATCC BAA-1705 and negative K. pneumoniae ATCC BAA-1706, and Escherichia coli ATCC 25922 obtained from BioMerieux were included in the study.

Statistical Analysis: Data obtained from this study were analyzed using descriptive statistics like percentage and proportion.

RESULTS: Of the 996 non-repeat isolates that were included in the study, the isolated organisms were E.coli $(n=538)$, Klebsiella pneumoniae $(n=350)$, Proteus mirabilis $(n=31)$, Proteus vulgaris $(n=21)$, Citrobacter freundii $(n=20)$, Citrobacter koseri $(n=16)$, Enterobacter cloacae $(n=7)$ and Enterobacter aerogenes $(n=13)$. The number of non-repeat isolates that were resistant to carbapenems (imipenem and meropenem) according to CLSI breakpoints was 66 of which isolates resistant to meropenem, imipenem, and both imipenem and meropenem were 37(56.06\%), $20(30.3 \%)$ and $9(13.63 \%)$ respectively. [Table1]

Among the thirty seven meropenem resistant isolates, the modified Hodge test was positive for $34(91.89 \%)$ of isolates, the metallo-beta-lactamase screening test with EDTA double disk synergy test, combined disk test and Etest were positive in $22(59.45 \%), 25(67.57 \%)$ and $25(67.57 \%)$ isolates respectively whereas KPC was observed in 5(13.5\%) isolates. [Table 2]

The modified Hodge test was positive in 18(90\%) of twenty imipenem resistant isolates. Seven of these isolates gave positive result by DDST but $9(45 \%)$ isolates exhibited $\geq 7 \mathrm{~mm}$ zone size enhancement in the combined disk test. MBL Etest also detected $9(45 \%)$ isolates. However, KPC was demonstrated in 3(15\%) clinical isolates. [Table 2]

Of the nine both meropenem and imipenem resistant isolates, the modified Hodge test picked up all the isolates with carbapenemase activity while the disk synergy test, combined disk test and Etest equally identified 5(55.56\%) isolates. The inhibitor method detected only one isolate as KPC. [Table 2] 
The co-production of both the KPC and MBL was observed in 3(4.54\%) isolates. Among the 66 carbapenem resistant isolates of Enterobacteriaceae, five bacterial strains were negative by the methods adopted for the detection of carbapenemases. [Table 3]

The MIC to imipenem and meropenem resistant isolates ranged from 4 to $\geq 256 \mu \mathrm{g} / \mathrm{ml}$ by the agar dilution method. [Table 4]

The carbapenem resistant isolates were not effective to almost all the antimicrobials tested except for polymycin B, colistin, tigecycline and amikacin. [Table 5]

DISCUSSION: Carbapenems are one of the essential antibiotics in the armamentarium against serious gram negative nosocomial infections due to the stability of these agents against the majority of $\beta$ lactamases and their high rate of permeation through bacterial outer membranes. However, in the last decade there has been increasing reports of carbapenem resistance in Pseudomonas aeruginosa, Acinetobacter spp and lately, Enterobacteriaceae. Carbapenem resistance has been attributed to various causes such as reduced expression of outer membrane proteins, increased efflux systems and production of carbapenemases which can inactivate carbapenems by causing their hydrolysis ${ }^{18}$.

We found that incidence of isolates resistant to meropenem was more than imipenem. It might be due to the fact that meropenem is well-tolerated and offers several potential advantages, including greater in vitro activity against Gram-negative pathogens, stability to renal dehydropeptidase-I(DHP-I), low risk of seizures and the option of bolus administration ${ }^{19}$. These might lead to possible greater use of meropenem over imipenem and hence the higher incidence of resistance.

Of the 66 carbapenem resistant isolates which were included in our study, only 61(92.42\%) isolates were found to produce the carbapenemase enzyme and the remaining five strains were found to be carbapenemase negative by MHT. MBL phenotypes were detected in only 39(59.09\%) isolates. Among the 22 strains which were positive by MHT and negative by DDST, CDT and Etest, six isolates of Klebsiella pneumoniae and three of E.coli were phenotypically identified as KPC producers. Tsakaris A et al similarly identified KPCs in K. pneumoniae, Escherichia coli or E. aerogenes ${ }^{15}$. This study also demonstrated the co-production of KPC and MBL in three K.pneumoniae. Similar finding was observed by Tsakaris A et al ${ }^{15}$. The production of both enzymes might contribute to their hydrolytic activity and levels of resistance to broad-spectrum beta-lactams, as well as to the possible co-migration of both enzymes. However, remaining MHT positive 10 isolates which were negative for KPCs and MBLs presumably had the other types of carbapenemase enzymes.

An another important cause of carbapenem resistance among Enterobacteriaceae might be overproduction of ESBL or Amp C enzyme with porin loss ${ }^{20}$. This could be the reason in five bacterial strains which were carbapenem resistant but negative by modified Hodge test.

Most of the Indian studies reported carbapenemase production in non-fermenters like Pseudomonas aeruginosa and Acinetobacter baumannii where the incidence ranged from $7 \%$ to

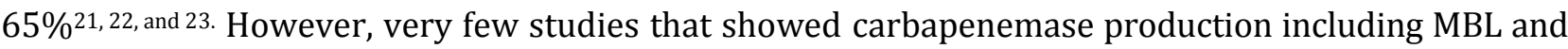
KPC in Enterobacteriaceae have been conducted in India so far and according to those reports, the occurrence of these enzymes ranged from $1 \%$ to $18 \% 24,25$, and 26 . The incidence of carbapenemases among Enterobacteriaceae in our hospital was 6\% (61/996) which fell in the lower side of the Indian ranged. 
Our study revealed high level of resistance (93-100\%) to $3^{\text {rd }}$ and $4^{\text {th }}$ generation cephalosporins, aztreonam, amoxicillin-clavulanate, pipercillin, pipercillin-tazobactam, gentamicin, fluoroquinolones (ciprofloxacin, levofloxacin) and cotrimoxazole by the carbapenemase producers. This was well agreed with the observations obtained in other studies 24, 26, 27.

In the present study, the combined disk test and MBL Etest were better methods for MBL detection than EDTA disk synergy test as they detected an additional two E coli, two Klebsiella pneumoniae and one Proteus mirabilis, which were missed by the disk synergy test. Though the reason for the difference in the performance of these two tests is not clear, similar results have been observed in other studies ${ }^{26,28}$. Combined disk test using both boronic acid and EDTA could help in differentiating MBLs from KPCs.

Various studies have suggested polymyxin B, tigecycline and colistin as the only treatment

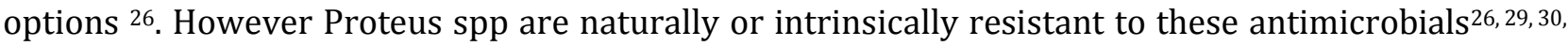
31. This was correlated with our finding that the five carbapenem resistant Proteus spp were resistant to these antimicrobials. In our study, polymyxin B and colistin turned out to be the most effective antimicrobial against carbapenemases followed by tigecycline and amikacin.

We could not discriminate the different types of carbapenemases due to unavailability of PCR in our hospital and perhaps, this is the major limitation in our studies. However, the need of the hour is simple, easy to perform, rapid and cost effective techniques which will be able to identify and differentiate resistant pathogens to improve patient outcome and counteract the escalation of resistance.

CONCLUSION: The present study revealed the occurrence of carbapenemases including MBL producing Enterobacteriaceae from a tertiary care hospital of eastern India and this could not be ignored. Based on our study, the modified Hodge test for the routine phenotypic detection of carbapenemases, combined disk test using EDTA for MBL production and boronic acid disk test for KPC, can be employed in any laboratory settings where molecular diagnostic techniques are not available to detect this important mechanism of antimicrobial resistance.

\section{REFERENCES:}

1. Yong D, Toleman MA, Giske CG, Cho HS, Sundman K, Lee K, Walsh TR. Characterization of a new metallo- $\beta$-lactamase gene, blaNDM-1, and a novel erythromycin esterase gene carried on a unique genetic structure in Sequence Type 14 from India. Antimicrob Agents Chemother 2009; 53:5046-5054.

2. Queenan AM, Bush K. Carbapenemases: the versatile $\beta$-lactamases. Clin Microbiol Rev 2007; 20:440-458.

3. Walsh TR, Toleman MA, Poirel L, Nordman P. Metallo $\beta$-lactamases: the quiet before the storm? Clin Microbiol Rev 2005; 18: 306-325.

4. Peleg AY, Franklin C, Bell JM, Spelmann DW. Dissemination of the metallo- $\beta$-lactamase gene bla IMP4 among gram-negative pathogens in a clinical setting in Australia. Clin Infect Dis 2005; 41: 1549-1556.

5. Nordmann P, Poirel L. Emerging carbapenemases in gram-negative aerobes. Clin Microbial Infect 2002; 8:321-331. 
6. Osano E, Arakawa Y, Wacharotayankun R, Ohta M, Horii T, Ito H, Yoshimura F, Kato N. Molecular characterization of an enterobacterial metallo beta-lactamase found in a clinical isolate of Serratia marcescens that shows imipenem resistance. Antimicrob Agents Chemother 1994; 38:71-78.

7. Miriagou V, Tzelepi E, Gianneli D, Tzouvelekis LS. Escherichia coli with a self-transferable, multiresistant plasmid coding for metallo-beta-lactamase VIM-1. Antimicrob Agents Chemother 2003; 47:395-397.

8. Yigit H, Queenan AM, Anderson GJ, Domenech-Sanchez A, Biddle JW, Steward CD, Alberti S, Bush K, Tenover FC. Novel carbapenem- hydrolyzing beta-lactamase, KPC-1, from a carbapenemresistant strain of Klebsiella pneumonia. Antimicrob Agents Chemother 2001; 45: 1151-1161.

9. Franklin C, Liolios L, Peleg AY. Phenotypic detection of carbapenem- susceptible metallo- $\beta$ lacatamase- producing Gram-negative bacilli in the clinical laboratory. J Clin Microbiol 2006; 44: 3139-3144.

10. Clinical and Laboratory Standards Institute (CLSI). Performance standards for antimicrobial


Standards Institute M100- S20; 2010.

11. Winn WC, Allen SD, Janda WM, Koneman EW, Procop GW. (2006) Introduction to microbiology part II: Guidelines for the Collection, Transport, Processing, Analysis and Reporting of Cultures from Specific Specimen Sources. In Koneman's Color Atlas and Textbook of Diagnostic Microbiology. $6^{\text {the }}$. Philadelpia: Lippincott William \& Wilkins.2006; pp 67-105.

12. Lee K, Chong Y, Shin HB, Kim YA, Yong D, Yum JH. Modified Hodge and disc synergy tests to screen metallo-beta-lactamase producing strains of Pseudomonas spp and Acinetobacter spp. Clin Microbiol Infect 2001; 7:88-91.

13. Lee K, Lim YS, Yong D, Yum JH, Chong Y. Evaluation of the Hodge Test and the Imipenem-EDTA Double-Disk Synergy Test for Differentiating Metallo- $\beta$-Lactamase Producing Isolates of Pseudomonas spp And Acinetobacter spp. J Clin Microbiol 2003;41: 4623-4626.

14. Tsakris A, Kristo I, Poulou A, Themeli-Digalaki K, Ikonomidis A, Petropoulou D, Pournaras S, Sofianou D. Evaluation of Boronic Acid Disk Tests for Differentiating KPC-Possessing Klebsiella pneumoniae Isolates in the Clinical Laboratory. J Clin Microbiol 2009, 47(2):362.

15. Tsakris A, Poulou A, Pournaras S, Voulgari E, Vrioni G, Themeli-Digalak K, Dimitra Petropoulou D, Sofianou D. A simple phenotypic method for the differentiation of metallo-beta-lactamases and class A KPC carbapenemases in Enterobacteriaceae clinical isolates. J Antimicrob Chemother 2010; 65: 1664-1671.

16. Arakawa Y, Shibata N, Shibayama K, Kurokawa H, Yagi T, Fujiwar H, Goto M. Convenient test for screening metallo-beta-lactamase producing gram negative bacteria by using thiol compounds. J Clin Microbiol 2000; 38:40-43.1

17. Yong D, Lee K, Yum JH, Shin HB, Rossolini GM, Chong Y. Imipenem EDTA disc method for differentiation of metallo beta lactamase producing clinical isolates of Pseudomonas spp and Acinetobacter spp. J Clin Microbiol 2002; 40:3798-3801.

18. Varaiya A, Kulkarni M, Bhalekar P, Dogra J. Incidence of Metallo-beta lactamase producing Pseudomonas aeruginosa in cancer and diabetic patients. Indian J Pathol Microbiol 2008; 51(2):200-203. 
19. Verwaest C. Belgian Multicenter Study Group, Meropenem versus imipenem/cilastatin as empirical monotherapy for serious bacterial infections in the intensive care unit. Clin Microbiol Infect 2000; 6:294-302.

20. Paterson DL. Resistance in gram-negative bacteria: Enterobacteriaceae. Am J Infect Control 2006; 34:20-28.

21. Gupta V, Datta P, Chander J. Prevalence of metallo-beta-lactamase (MBL) producing Pseudomonas spp and Acinetobacter spp in a tertiary care hospital in India. J Infect 2006;52:311-314.

22. Jesudason MV, Kandathil AJ, Balaj V. Comparison of two methods to detect carbapenemase and metallo-beta-lactamase production in clinical isolates. Indian J Med Res 2005;121:780-783.

23. Chakraborty D, Basu S, Das S. A study on infections caused by metallo-beta- lactamase producing gram negative bacteria in intensive care unit patients. Am J Infect Dis 2010; 6:34-39.

24. Deshmukh DG, Damle AS, Bajaj JK, Bhakre JB, Patwardhan NS. Metallo- $\beta$-lactamase-producing clinical isolates from patients of a tertiary care hospital. J Lab Physicians 2011;3(2):93-97.

25. Deshpande P, Rodrigues C, Shetty A, Kapadia F, Hedge A, Soman R. New Delhi Metallo-betalactamase (NDM-1) in Enterobacteriaceae: Treatment options with Carbapenems Compromised. J Assoc Physcians Ind 2010;58:147-149.

26. Rai S, Manchanda V, Singh NP, Kaur IR. Zinc-dependent carbapenemases in clinical isolates of family Enterobacteriaceae. Ind J Med Microbiol 2011;29(3):275-279.

27. Sarma JB, Bhattacharya PK, Kalita D, Rajbangshi M. Multidrug-resistant Enterobacteriaceae including metallo- $\beta$-lactamase producers are predominant pathogens of healthcare-associated infections in an Indian teaching hospital. Ind J Med Microbiol 2011; 29(1):22-27

28. Behera B, Mathur P, Das A, Kapil A, Sharma V.) An evaluation of four different phenotypic techniques for detection of metallo- $\beta$-lactamase producing Pseudomonas aeruginosa. Ind J Med Microbiol 2008; 26(3):233-237.

29. Biswas S, Brunel JM, Dubus JC, Gaubert MR, Rolain JM. Colistin: An update of the antibiotic of the $21^{\text {st }}$ century. Expert Rev Anti Infect Ther 2012;10(8): 1-17.

30. Souli M, Kontopidou FV, Koratzanis E, Antoniadou A, Giannitsioti E, Evangelopoulou P, Kannavaki S, Giamarellou H. In Vitro Activity of Tigecycline against Multiple-Drug-Resistant, Including Pan-Resistant, Gram-Negative and Gram-Positive Clinical Isolates from Greek Hospitals. Antimicrob Agents Chemother 2006;50(9): 3166-3169.

31. Swierzko AS, Kirikae T, Kirikae F, Hirata M, Cedzynski M, Ziolkowski A, Hirai Y, Kusumoto S, Yokochik T, Nakano M. Biological activities of lipopolysaccharides of Proteus spp. and their interactions with polymyxin B and an 18-kDa cationic antimicrobial proteinCAP18)-derived peptide. J Med Microbiol 2000;49:127-138. 


\begin{tabular}{|l|c|c|c|}
\hline $\begin{array}{c}\text { Microorganisms } \\
\text { (No. of carbapenem } \\
\text { resistant isolates) }\end{array}$ & $\begin{array}{c}\text { Resistant to } \\
\text { Meropenem (\%) }\end{array}$ & $\begin{array}{c}\text { Resistant to } \\
\text { Imipenem (\%) }\end{array}$ & $\begin{array}{c}\text { Resistant to } \\
\text { Both (\%) }\end{array}$ \\
\hline E.coli (34) & $18(52.94)$ & $9(26.47)$ & $7(20.58)$ \\
\hline Klebsiella pneumoniae (22) & $11(50)$ & $9(40.9)$ & $2(9)$ \\
\hline Proteus mirabilis (3) & $2(66.67)$ & $1(33.33)$ & 0 \\
\hline Proteus vulgaris (2) & $1(50)$ & $1(50)$ & 0 \\
\hline Citrobacter freundii (2) & $2(100)$ & 0 & 0 \\
\hline Citrobacter koseri (1) & $1(100)$ & 0 & 0 \\
\hline Enterobacter cloacae (2) & $2(100)$ & 0 & 0 \\
\hline \multicolumn{1}{|c|}{ Total (66) } & $37(56.06)$ & $20(30.3)$ & $9(13.63)$ \\
\hline
\end{tabular}

Table 1. Bacterial isolates showing resistance to carbapenems

\begin{tabular}{|c|c|c|c|c|c|c|}
\hline \multirow{2}{*}{$\begin{array}{c}\text { Carbapenem } \\
\text { resistant } \\
\text { (No. of isolates) }\end{array}$} & \multirow{2}{*}{$\begin{array}{c}\text { Carbapenemases } \\
\text { MHT (\%) }\end{array}$} & \multicolumn{3}{|c|}{ MBL } & \multirow[b]{2}{*}{$\begin{array}{l}\text { KPC } \\
(\%)\end{array}$} & \multirow{2}{*}{$\begin{array}{c}\text { MBL+ } \\
\text { KPC } \\
(\%)\end{array}$} \\
\hline & & $\begin{array}{l}\text { DDST } \\
(\%)\end{array}$ & $\begin{array}{l}\text { CDT } \\
\text { (\%) }\end{array}$ & $\begin{array}{l}\text { Etest } \\
(\%)\end{array}$ & & \\
\hline Meropenem (37) & $34(91.89)$ & $22(59.45)$ & $25(67.57)$ & $25(67.57)$ & $5(13.5)$ & $2(5.4)$ \\
\hline Imipenem (20) & $18(90)$ & $7(35)$ & $9(45)$ & $9(45)$ & $3(15)$ & $1(5)$ \\
\hline $\begin{array}{l}\text { Both meropenem \& } \\
\text { imipenem (9) }\end{array}$ & $9(100)$ & $5(55.56)$ & $5(55.56)$ & $5(55.56)$ & $1(55.56)$ & 0 \\
\hline Total (66) & $61(92.42)$ & $34(51.51)$ & $39(59.09)$ & $39(59.09)$ & $9(13.63)$ & $3(4.54)$ \\
\hline
\end{tabular}

Table 2. Distribution of carbapenemases among the carbapenems

MBL- Metallo-beta lactamases, KPC- K. pneumoniae carbapenemase, MHT-Modified Hodge test, DDST-EDTA Double disk synergy test, CDT-Combined disk test.

\begin{tabular}{|c|c|c|c|c|c|c|}
\hline \multirow{2}{*}{$\begin{array}{l}\text { Microorganisms } \\
\text { (No. of carbapenem } \\
\text { resistant isolates) }\end{array}$} & \multirow{2}{*}{$\begin{array}{c}\text { Carbapenemases } \\
\text { MHT (\%) }\end{array}$} & \multicolumn{3}{|c|}{ MBL } & \multirow{2}{*}{ KPC (\%) } & \multirow{2}{*}{$\begin{array}{c}\text { MBL+ } \\
\text { KPC } \\
(\%)\end{array}$} \\
\hline & & DDST (\%) & CDT (\%) & Etest (\%) & & \\
\hline E.coli (34) & $29(85.29)$ & $19(55.88)$ & $21(61.76)$ & $21(61.76)$ & $3(8.82)$ & 0 \\
\hline Klebsiella pneumoniae (22) & $22(100)$ & $11(50)$ & 13(59.09) & 13(59.09) & $6(27.27)$ & $3(13.63)$ \\
\hline Proteus mirabilis (3) & $3(100)$ & $1(33.33)$ & $2(66.67)$ & $2(66.67)$ & 0 & 0 \\
\hline Proteus vulgaris (2) & $2(100)$ & $1(50)$ & $1(50)$ & $1(50)$ & 0 & 0 \\
\hline Citrobacter freundii (2) & $2(100)$ & $1(50)$ & $1(50)$ & $1(50)$ & 0 & 0 \\
\hline Citrobacter koseri (1) & $1(100)$ & 0 & 0 & 0 & 0 & 0 \\
\hline Enterobacter cloacae (2) & $2(100)$ & $1(50)$ & $1(50)$ & $1(50)$ & 0 & 0 \\
\hline Total (66) & $61(92.42)$ & $34(51.51)$ & $39(59.09)$ & $39(59.09)$ & $9(13.63)$ & $3(4.54)$ \\
\hline
\end{tabular}

Table 3. Distribution of carbapenemases among the Enterobacteriaceae species

MBL- Metallo-beta lactamases, KPC- K. pneumoniae carbapenemase, MHT-Modified Hodge test, DDST-EDTA Double disk synergy test, CDT-Combined disk test. 


\begin{tabular}{|l|c|c|c|c|c|c|c|c|c|}
\hline \multicolumn{1}{|c|}{$\begin{array}{c}\text { Carbapenemases/ } \\
\text { carbapenems }\end{array}$} & \multicolumn{10}{|c|}{ No of isolates with MIC $(\boldsymbol{\mu g} / \mathbf{m l})$} \\
\cline { 2 - 10 } & $\mathbf{0 . 5}$ & $\mathbf{1}$ & $\mathbf{2}$ & $\mathbf{4}$ & $\mathbf{8}$ & $\mathbf{1 6}$ & $\mathbf{3 2}$ & $\mathbf{6 4}$ & $\mathbf{2 1 2 8}$ \\
\hline KPC(n=9) & & & & & & & & & \\
Imipenem(n=3) & 0 & 0 & 0 & 0 & 1 & 0 & 1 & 1 & 0 \\
Meropenem(n=5) & 0 & 0 & 0 & 0 & 0 & 1 & 1 & 2 & 1 \\
Both(n=1) & 0 & 0 & 0 & 0 & 0 & 0 & 0 & 0 & 1 \\
\hline MBL(n=39) & & & & & & & & & \\
Imipenem(n=9) & 0 & 0 & 0 & 0 & 2 & 1 & 1 & 2 & 3 \\
Meropenem(n=25) & 0 & 0 & 0 & 1 & 3 & 5 & 4 & 5 & 7 \\
Both(n=5) & 0 & 0 & 0 & 0 & 1 & 0 & 2 & 1 & 0 \\
\hline KPC+MBL (n=3) & & & & & & & & & \\
Imipenem(n=1) & 0 & 0 & 0 & 0 & 0 & 0 & 1 & 0 & 0 \\
Meropenem(n=2) & 0 & 0 & 0 & 0 & 0 & 0 & 0 & 2 & 0 \\
Both(n=0) & 0 & 0 & 0 & 0 & 0 & 0 & 0 & 0 & 0 \\
\hline Others(n=10) & & & & & & & & & \\
Imipenem(n=5) & 0 & 0 & 0 & 1 & 0 & 2 & 1 & 2 & 0 \\
Meropenem(n=2) & 0 & 0 & 0 & 0 & 0 & 0 & 1 & 1 & 0 \\
Both(n=3) & 0 & 0 & 0 & 0 & 1 & 0 & 0 & 1 & 1 \\
\hline
\end{tabular}

Table 4. Distribution of carbapenem MICs for the carbapenemase-positive clinical isolates

MBL- Metallo-beta lactamases, KPC- K. pneumoniae carbapenemase.

\begin{tabular}{|l|c|}
\hline \multicolumn{1}{|c|}{ Antimicrobials } & Resistant isolates (\%) \\
\hline Ceftazidime & $64(96.96 \%)$ \\
\hline Cefotaxime & $64(96.96 \%)$ \\
\hline Ceftriaxone & $66(100 \%)$ \\
\hline Cefepime & $64(96.96 \%)$ \\
\hline Aztreonam & $65(98.48 \%)$ \\
\hline Amoxicillin-clavulanic acid & $64(96.96 \%)$ \\
\hline Piperacillin & $65(98.48 \%)$ \\
\hline Piperacilin/tazobactam & $63(95.45 \%)$ \\
\hline Gentamicin & $62(93.93 \%)$ \\
\hline Amikacin & $45(68.18 \%)$ \\
\hline Levofloxacin & $62(93.93 \%)$ \\
\hline Ciprofloxacin & $66(100 \%)$ \\
\hline Cotrimoxazole & $66(100 \%)$ \\
\hline Polymyxin B & $7(10.6 \%)$ \\
\hline Colistin & $7(10.6 \%)$ \\
\hline Tigecycline & $9(13.63 \%)$ \\
\hline \multicolumn{2}{|c|}{ Table 5. Antimicrobial susceptibility pattern } \\
of 66 carbapenem resistant isolates
\end{tabular}




\section{ORIGINAL ARTICLE}

\section{AUTHORS:}

1. Rajkumar Manojkumar Singh

2. Soma Sarkar

3. Puranjay Saha

4. Manideepa Sengupta

\section{PARTICULARS OF CONTRIBUTORS:}

1. Assistant Professor, Department of Microbiology, Jawaharlal Nehru Institute of Medical Sciences, Imphal.

2. Assistant Professor, Department of Microbiology, Medical College \& Hospital, Kolkata.

3. Associate Professor, Department of Microbiology, Malda Medical College \& Hospital, Malda, West Bengal.
4. Professor, Department of Microbiology, Medical College \& Hospital, Kolkata.

\section{NAME ADDRESS EMAIL ID OF THE CORRESPONDING AUTHOR:}

Dr. Rajkumar Manojkumar Singh, Department of Microbiology, Jawaharlal Nehru Institute of Medical Sciences, Imphal - 795005, Manipur, India.

E-mail: rkmksingh@gmail.com

Date of Submission: 20/01/2014.

Date of Peer Review: 21/01/2014.

Date of Acceptance: 30/01/2014.

Date of Publishing: 04/02/2014. 